ISSN 2236-0859

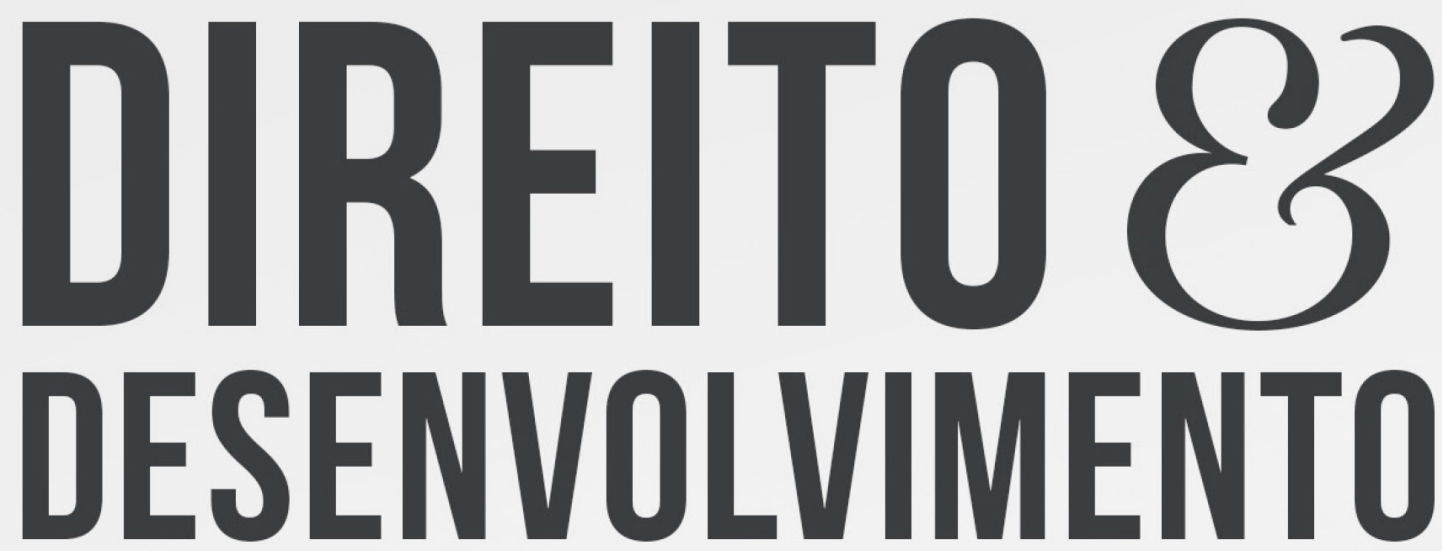

REVISTA DO PROGRAMA DE PÓS-GRADUACÃO EM DIREITO MESTRADO EM DIREITO E DESENVOLVIMENTO SUSTENTÁVEL

\title{
A ATUAÇÃO RESOLUTIVA DO MINISTÉRIO PÚBLICO FEDERAL NA ÁREA DA SAUUDE PÚBLICA
}

LUIS HENRIQUUE DA SILVA DE PAIVA

DJALMA LEANDRO JÚNIOR 


\section{A ATUAÇÃO RESOLUTIVA DO MINISTÉRIO PÚBLICO FEDERAL NA ÁREA DA SAÚDE PÚBLICA}

\section{THE RESOLUTIVE ACTION OF THE FEDERAL PUBLIC MINISTRY IN THE PUBLIC HEALTH AREA}

Recebido: 27/01/2020

Aprovado: 03/06/2020

\author{
Luis Henrique da Silva de Paiva ${ }^{1}$ \\ Djalma Leandro Júnior ${ }^{2}$
}

\section{RESUMO:}

Este artigo argumenta que a atuação extrajudicial do Ministério Público Federal na área da tutela coletiva do direito à saúde tem servido para a implementação e o aperfeiçoamento de políticas de saúde pública, tendo a Instituição atuado de forma resolutiva e contribuído para minimização da judicialização dessas questões. O objetivo é explorar as medidas institucionais adotadas pelo Conselho Nacional do Ministério Público e pelo Ministério Público Federal quanto ao fomento da atuação resolutiva dos seus Órgãos, bem como a utilização dos meios extrajudiciais legalmente atribuídos à Instituição: inquéritos civis e procedimentos preparatórios, compromissos de ajustamento de conduta e recomendações, como instrumentos de adequação da gestão do sistema público de saúde às diretrizes e aos direitos assegurados na Constituição Federal. São utilizados elementos conceituais, a teoria sobre o Ministério Público demandista e resolutivo e sobre os instrumentos extrajudiciais do MP, a análise de dados primários e secundários, bem como questionários direcionados aos gestores documentais do Ministério Público Federal, com o intuito de analisar em que medida a atuação extrajudicial do Ministério Público Federal tem servido para se alcançar soluções negociadas às demandas na área da saúde pública. Os resultados indicam que o Ministério Público Brasileiro tem avançado na sua atuação extrajudicial, mediante a adoção de estratégias institucionais na busca de resolutividade das demandas coletivas. No caso do Ministério Público Federal, os resultados indicam que a Instituição tem alcançado bons índices de efetividade em relação aos termos de ajustamento de conduta celebrados, evitando a judicialização de questões atinentes à saúde pública.

Palavras-chave: Ministério Público Federal. Atuação extrajudicial. Saúde Pública. Termos de Ajustamento de Conduta. Judicialização.

K41.

\footnotetext{
1 Possui graduação em Ciências Sociais pela Universidade Federal de Minas Gerais (1992), com mestrados em Sociologia pela Universidade Estadual de Campinas (1995) e em Política Social pela Universidade de Southampton (2009), Reino Unido. Concluiu o doutorado em Sociologia e Política pela Universidade Federal de Minas Gerais (2002). Atualmente é membro da carreira de Especialista em Políticas Públicas e Gestão Governamental, vinculada ao Ministério do Planejamento, Orçamento e Gestão e professor permanente do Mestrado em Administração Pública do Instituto Brasiliense de Direito Público - IDP.. E-mail: lhspaiva1@gmail.com

2 Possui graduação em Direito (1996), especialização em Gestão na Administração Pública (2008) e mestrado em Administração Pública (2018). É integrante da carreira de Analista Jurídico do Ministério Público da União. Atualmente lotado no Ministério Público Federal em Goiás, exerce as atribuições de Assessor de Planejamento e Gestão Estratégica (2018), com passagens profissionais na ProcuradoriaGeral da República na qual atuou como Secretário de Administração Adjunto (2015-2016) e Assessor-Chefe da Assessoria Técnica da Secretaria-Geral do MPU-MPF (2016-2018); na Procuradoria da República em Goiás, onde atuou como Secretário Estadual (2013-2015), Coordenador de Administração (2006-2013) e Assessor Especial (1998-2006). Atuou, também como Assessor na Casa Civil do Governo do Estado do Tocantins (1997-1998). E-mail: djalma@mpf.mp.br
} 


\begin{abstract}
:
This study argues that the extrajudicial performance of the Federal Public Ministry (MPF) in the area of collective tutelage of health rights has served to implement and improve policies in the area of public health, and the Institution has acted resolutively, so that it has contributed to minimize the judicialization of these issues. We explore the institutional measures adopted by the National Council of the Public Prosecution Service and the Federal Public Prosecutor's Office to promote the resolution of their Offices and the use of extrajudicial means legally attributed to the Institution, namely: investigations and preparatory procedures, commitments of adjustment of conduct and recommendations, as instruments of adaptation of the management of the public health system to the guidelines and the rights guaranteed in the Federal Constitution. We use conceptual elements, the theory on the prosecution and resolution Public Prosecutor's Office and on the extrajudicial instruments of the MPF, the analysis of primary and secondary data and questionnaires directed to documentary managers of the MPF, to analyze to what extent the extrajudicial performance of the MPF has served to reach negotiated solutions to the demands in the area of public health. The results suggest that the Brazilian Public Prosecutor's Office has advanced in the perspective of its extrajudicial action, by adopting institutional strategies in search of resolution of collective demands. The results indicate that the Institution has achieved good levels of effectiveness in relation to the terms of conduct adjustment, to avoid the judicialization of issues related to public health.
\end{abstract}

Keywords:Federal Public Ministry. Extrajudicial performance. Public health. Terms of Conduct Adjustment. Judicialization.

K41.

\title{
INTRODUÇÃO
}

Este artigo tem por objetivo principal estudar que medida a atuação extrajudicial do Ministério Público Federal está sendo efetiva para reduzir a judicialização de demandas na área da saúde. No Brasil, a judicialização da saúde é decorrência do contexto jurídico trazido pela nova ordem constitucional (CASAGRANDE, 2008).

A sedimentação do vínculo entre direito e saúde decorreu de amplas discussões entre grupos de pressão, sociedade civil e Estado (CNJ, 2015). Isso possibilitou aos cidadãos maiores níveis de acesso à cidadania e maior consciência sobre os seus direitos, com um acesso mais facilitado ao Judiciário que, por sua vez, passou a ser reconhecido como um importante mecanismo para a efetivação de políticas públicas (NETO, 2015).

Conforme pesquisa realizada pelo CNJ (2015, p. 9), "a progressiva constitucionalização que os direitos sociais passaram na década de 1980, associada aos desafios de implementação efetiva por parte do Estado, fez com que tais direitos fossem cada vez mais submetidos ao crivo das instituições jurídicas para a sua efetivação".

Embora por um lado seja reconhecido que a judicialização tem contribuído com o aperfeiçoamento e a instituição de novas políticas públicas de saúde, por outro, existem diversas críticas a esse fenômeno. De forma geral, pode-se dizer que os aspectos negativos decorrem da ausência de amplo conhecimento sobre todo o problema que existe em torno de questões mais abrangentes em matéria de saúde, de modo que não é o Judiciário quem melhor pode fazer as opções sobre quem deve ou não receber determinado tratamento. 
De fato, saúde e direito são campos bastante politizados no Brasil (CNJ, 2015), onde buscar o atendimento no SUS, por meio de ações judiciais, tem se tornado cada dia mais comum. No período de 2009 a 2015, por exemplo, o gasto do Ministério da Saúde apenas com medicamentos deferidos judicialmente foi da ordem de $\mathrm{R} \$ 3,4$ bilhões em valores de 2015 . Entre 2010 e 2016, o gasto com as ações judiciais tendo o fornecimento de medicamentos como objeto passou de $\mathrm{R} \$ 199,6$ milhões para $\mathrm{R} \$ 1,3$ bilhão, um crescimento de 547\% (IPEA, 2018).

Neste trabalho, pretende-se explorar o papel do Ministério Público Federal como indutor da implementação de medidas visando ao cumprimento e ao aperfeiçoamento das políticas sociais atinentes ao sistema público de saúde, mais especificamente, ao subsistema de acesso universalizado, financiado por recursos públicos e gratuito, o denominado Sistema Único de Saúde.

Propõe-se como problema da pesquisa a seguinte indagação: os meios extrajudiciais utilizados pelo Ministério Público Federal -celebração de termo de ajustamento de conduta e expedição de recomendação -têm sido suficientes, por si só, para a efetivação das políticas públicas de saúde e induzem o gestor público da área a implementar as ações necessárias sob sua responsabilidade? $\mathrm{Ou}$, se a despeito da prática desses atos, tem sido necessária a judicialização das questões que aportam à Instituição?

Este artigo está dividido em quatro seções. A primeira dedica-se, a partir da revisão da literatura, a discutir as modalidades de atuação do Ministério Público (demandista e resolutiva) e a demonstrar de que forma nesta segunda espécie a instituição operacionaliza a sua atuação na esfera extrajudicial.

A segunda seção do artigo trata das estratégias e das iniciativas recentemente adotadas no âmbito do Conselho Nacional do Ministério Público, visando fomentar o papel resolutivo do Ministério Público Brasileiro. É dada ênfase à Política Nacional de Fomento à Atuação Resolutiva do Ministério Público Brasileiro, assim como à Carta de Brasília.

A terceira seção descreve a metodologia adotada e os dados coletados para as análises da atuação do Ministério Público no âmbito da saúde. A quarta seção traz a análise e a discussão dos resultados de um levantamento dos termos de ajustamento de conduta (TAC) celebrados e das recomendações expedidas no período compreendido na pesquisa (janeiro de 2013 a dezembro de 2015). O artigo se encerra com conclusões do trabalho que traz a síntese crítica dos achados empíricos e teóricos, além das limitações do estudo realizado e as perspectivas quanto a futuras agendas de pesquisa.

\section{OS MODELOS DE ATUAÇÃO DO MINISTÉRIO PÚBLICO}

Quanto à atuação dos órgãos de execução do Ministério Público, a doutrina a divide em dois segmentos : a atuação demandista e a atuação resolutiva. A primeira, fundada em demandas judiciais; a segunda pautada pela utilização de mecanismos extraprocessuais para a resolução de conflitos. No que se refere a esses perfis de atuação, observa-se que o modelo demandista que transfere ao Poder Judiciário a resolução das demandas sociais é ainda o prevalecente (GOULART, 1998).

Ao analisar do novo perfil constitucional do Ministério Público implantado pela Constituição da República de 1988, Almeida (2013, p. 47) ressalta, dentre outros aspectos, que:

[...] o Estado Democrático de Direito, diferentemente das outras formas de Estado, tem um compromisso nuclear: transformar a realidade social na busca da igualdade material quanto ao acesso efetivo a bens e outros valores [...]. Defende a priorização da atuação preventiva, a ampliação e a estruturação do modelo do Ministério Público resolutivo 
e ainda sustenta que [....] a atuação extrajudicial da Instituição é fundamental para a proteção e efetivação dos direitos ou interesses sociais [...]. Aduz, também, que, no exercício desse papel, o Ministério Público torna-se [...] um canal fundamental para o acesso da sociedade, especialmente das suas partes mais carentes e dispersas, a uma ordem jurídica realmente mais legítima e justa [...].

Na mesma linha de entendimento, Lima (2013, p. 473) ressalta os perfis demandista e resolutivo do Ministério Público, sendo o primeiro aquele que não resolve os conflitos pelo consenso, pela composição, e o último o que alcança a harmonização entre os diversos interesses em jogo. Destaca a posição doutrinária que distingue o papel do Ministério Público.

Lima (2013) atribui a esse caráter de resolutividade duas modalidades: a preventiva quando se evitam lesões e a repressiva quando a lesão ao direito já se consumou. Na primeira, tem-se o inquérito civil público, a recomendação, o termo de ajustamento de conduta e o procedimento administrativo como principais instrumentos; na segunda, há a composição sobre o conflito, por meio do termo de ajustamento de conduta.

Goulart (2013) entende que, no modelo demandista, a atuação cível do Ministério Público restringe-se ao processo judicial, como mero operador processual, ora funcionando como órgão agente (autor de ações civis Públicas), ora como órgão interveniente (custos legis). Observa, ainda, que essa linha de atuação restrita compromete, sobretudo, a efetividade do trabalho do Ministério Público na tutela dos interesses coletivos e difusos, reduzindo o inquérito civil a simples instrumento de coleta das provas necessárias ao ajuizamento de ação civil pública, transferindo ao Poder Judiciário a solução de todas as questões de natureza transindividual apresentadas ao Ministério Público.

O Ministério Público demandista afigura-se não efetivo na área cível, pois, ao ser dependente do Poder Judiciário, pode induzir a resultados desastrosos no campo da defesa do regimento democrático e da tutela dos interesses transindividuais. No papel resolutivo o Ministério Público assume o papel de agente político que lhe foi confiado pela sociedade, superando a perspectivas meramente processual de suas intervenções, tornando-se o Judiciário uma alternativa excepcional de sua atuação (GOULART, 2013).

Júnior, J. (2013, p. 102), reafirmando a relevância do Ministério Público como órgão de defesa social e de controle dos atos da Administração Pública, ressalta que, com o advento da Constituição de 1988, a Instituição assumiu um novo perfil, sobretudo diante do seu aparelhamento:

\footnotetext{
“[...] com os predicamentos apropriados, num relevo jamais visto em nenhum outro texto constitucional, mesmo em outros países. [...]" o que reforça o seu perfil de órgão pró-ativo, "[...] de postura resolutiva, atuando, por si só, com autonomia e independência absoluta na solução e prevenção dos conflitos sociais".
}

Oliveira (2013, p. 246) defende que, em razão da nova postura resolutiva do Ministério Público brasileiro, diversos mecanismos passaram ter uma utilização expressiva pelos membros da instituição, indo além do âmbito do inquérito civil, procedimentos preparatórios ou outros procedimentos adotados no âmbito interno da Instituição.

No intuito de se obter soluções negociadas independentemente da participação do Poder Judiciário, Oliveira (2013) pontua a importância da realização de audiências públicas, com enfoque nitidamente democrático e que se revela meio de significativa eficácia de onde se extraem abordagens participativas para o enfrentamento de problemas vivenciados por determinada comunidade.

Oliveira (2013) ressalta que a utilização desses instrumentos extrajudiciais têm apresentado "grande eficácia" sustentando como razões desse entendimento que há interesse 
das pessoas físicas e jurídicas destinatárias das recomendações e dos termos de ajustamento de conduta em adequar os seus procedimentos ou atos inadequados aos preceitos das normas, evitando os seus procedimentos ou atos inadequados aos preceitos das normas, bem como todos os desgastes que naturalmente um processo judicial pode causar tanto no aspecto financeiro quanto, conforme o caso, na própria imagem perante a opinião pública.

Válido destacar que não há uma forma de atuação do Ministério Público que se possa afirmar a mais adequada, quer seja processual ou extrajudicial, dentro ou fora do juízo. É no caso concreto que se deve avaliar a opção do instrumento ou da via mais apta para o cumprimento da missão institucional. Entretanto, há de se reconhecer o seu viés resolutivo na medida em que anuncia que o Ministério Público, na posição de defensor do ordenamento jurídico, do regimento democrático e da sociedade, conforme preconizado pelo art. 127, caput, da CF, por intermédio dos seus órgãos de execução, passou a ter um novo papel de mediação, inclusão e mobilização social, exercendo assim papel fundamental para "[...] a implementação das políticas públicas e dos direitos fundamentais previstos na Constituição da República”.

\subsection{Estratégias e iniciativas visando fomentar o papel resolutivo do Ministério Público brasileiro}

Na linha do que a doutrina convencionou denominar atuação resolutiva, percebeu-se que tanto o órgão de fiscalização, o Conselho Nacional do Ministério Público (CNMP)3 ${ }^{3}$ quanto os órgãos de coordenação e revisão do Ministério Público Federal, têm dedicado parte de suas agendas ao desenvolvimento e à implementação de iniciativas que visam ao fomento dessa modalidade de atuação institucional.

Em abril de 2017, foi publicada a Recomendação no 54/2017, que dispõe sobre a Política Nacional de Fomento à Atuação Resolutiva do Ministério Público Brasileiro (CNMP, 2017b). $\mathrm{O}$ instrumento trouxe em seu conteúdo nove considerandos que lhe dão o suporte fático e jurídico que justificam e motivam a edição do ato.

Trata-se de importante marco na evolução do papel constitucional do Ministério Público Brasileiro, na medida em que explicita de forma patente a priorização de soluções negociadas extrajudicialmente, reconhecendo a via judicial apenas como uma das alternativas de atuação institucional, de caráter residual.

Como fonte motivadora da norma, é citada a Política Nacional de Incentivo à Autocomposição no âmbito do Ministério Público, prevista na Resolução no 118/2014, que trata da adoção de mecanismos de autocomposição pacífica dos conflitos. Por fim, confere ênfase à necessidade da atuação crescentemente resolutiva, orientada para a “[...] resolução concreta

\footnotetext{
3 O Conselho Nacional do Ministério Público atua em prol do cidadão executando a fiscalização administrativa, financeira e disciplinar do Ministério Público no Brasil e de seus membros, respeitando a autonomia da instituição. O órgão foi criado em 30 de dezembro de 2004, pela Emenda Constitucional no 45, e tem sede em Brasília-DF. As suas atribuições encontram-se previstas no art. 130-A, § 2º, da Constituição da República, nos seguintes termos: "§ 2o Compete ao Conselho Nacional do Ministério Público o controle da atuação administrativa e financeira do Ministério Público e do cumprimento dos deveres funcionais de seus membros, cabendo lhe: I zelar pela autonomia funcional e administrativa do Ministério Público, podendo expedir atos regulamentares, no âmbito de sua competência, ou recomendar providências; II zelar pela observância do art. 37 e apreciar, de ofício ou mediante provocação, a legalidade dos atos administrativos praticados por membros ou órgãos do Ministério Público da União e dos Estados, podendo desconstituí-los, revê-los ou fixar prazo para que se adotem as providências necessárias ao exato cumprimento da lei, sem prejuízo da competência dos Tribunais de Contas; III receber e conhecer das reclamações contra membros ou órgãos do Ministério Público da União ou dos Estados, inclusive contra seus serviços auxiliares, sem prejuízo da competência disciplinar e correcional da instituição, podendo avocar processos disciplinares em curso, determinar a remoção, a disponibilidade ou a aposentadoria com subsídios ou proventos proporcionais ao tempo de serviço e aplicar outras sanções administrativas, assegurada ampla defesa; IV rever, de ofício ou mediante provocação, os processos disciplinares de membros do Ministério Público da União ou dos Estados julgados há menos de um ano; V elaborar relatório anual, propondo as providências que julgar necessárias sobre a situação do Ministério Público no País e as atividades do Conselho, o qual deve integrar a mensagem prevista no art. 84, XI.
} 
das situações de inefetividade dos direitos cuja defesa e proteção é incumbida à Instituição [...]" (CNMP, 2017b).

Outra importante iniciativa institucional de manifesto estímulo à atuação resolutiva do Ministério Público Brasileiro é a edição da Carta de Brasília. Fruto de amplos debates e discussões, materializa acordo celebrado entre a Corregedoria Nacional e as Corregedorias do Ministério Público dos estados e as do Ministério Público da União, no sentido de explicitar

[...] premissas para a concretização do compromisso institucional de gestão e atuação voltadas à atuação resolutiva, em busca de resultados de transformação social, prevendo diretrizes estruturantes do MP, de atuação funcional de membros e relativas às atividades de avaliação, orientação e fiscalização dos órgãos correcionais (CNMP, 2017a).

De conteúdo paradigmático e abrangência nacional sobre todo o Ministério Público Brasileiro, o acordo traz importantes balizas sobre as atividades a serem desempenhadas pelos órgãos correicionais, em que torna nítida a preocupação em privilegiar a atuação extrajudicial eficiente, efetiva e célere em relação à judicialização das questões que aportam à instituição.

No eixo de considerações sobre os modelos constitucionais do Ministério Público o documento classifica dois tipos: o que atua perante o Poder Judiciário com o objetivo de obter tutela por adjudicação e o que atua extrajudicialmente como intermediador da pacificação social visando a resolução dos conflitos, controvérsias e problemas de modo consensual.

$\mathrm{O}$ instrumento também confere importante destaque à resolutividade da atuação do Ministério Público, estabelecendo que esta pressupõe o alinhamento entre a atividade funcional qualitativa e regular de seus membros com a adoção de práticas institucionais estruturantes efetivamente ajustadas aos objetivos estratégicos pretendidos.

Também se verifica o reforço da adoção de postura resolutiva amparada no compromisso com ganhos de efetividade na atuação institucional sendo que, para tanto, é exigido o esgotamento das alternativas de resolução extrajudicial dos conflitos, controvérsias e problemas, com o incremento da utilização dos instrumentos como a recomendação, termo de ajustamento de conduta, projetos sociais e adoção do arquivamento resolutivo sempre que essa medida for a mais adequada.

Ressalta-se que na Carta também foi objeto de atenção o alcance da atuação institucional, sendo recomendada a priorização nas matérias de tutela coletiva. Sem embargo disso, cuidou de restringir a propositura de ações individuais apenas aos casos em que a medida seja imprescindível; na mesma linha, sem desmerecer a importância das demandas de caráter individual, propõe sejam objeto dos encaminhamentos pertinentes.

No que tange ao controle qualitativo, a par da regularidade e da resolutividade da atuação do Ministério Público, é dada prioridade aos procedimentos extrajudiciais em tramitação, com foco, entre outros aspectos, na natureza, complexidade e alcance social da matéria. Ainda sob este aspecto, a diretriz é no sentido de que será aferida a utilização eficiente de mecanismos de resolução consensual de conflitos, controvérsias e problemas; e a utilização eficiente e objetiva dos recursos extrajudiciais e judiciais visando à prevenção e à tempestiva correção de ilícitos.

Especificamente quanto aos instrumentos de atuação extrajudicial aqui analisados, termos de ajustamento de conduta, e recomendações, são estabelecidos alguns fatores que serão considerados nas atividades correcionais, como os destacados a seguir: 


\section{Fatores a Serem Considerados nas Atividades Correicionais}

\begin{tabular}{|c|c|}
\hline $\begin{array}{l}\text { Instrumentos } \\
\text { de atuação }\end{array}$ & Fatores \\
\hline \multirow{10}{*}{$\begin{array}{l}\text { Termos de } \\
\text { Ajustamento } \\
\text { de Conduta }\end{array}$} & Apresentação dos devidos fundamentos constitucionais ou legais. \\
\hline & Delimitação do fato que resultou na existência ou na iminência do dano \\
\hline & Caracterização do dano. \\
\hline & $\begin{array}{c}\text { Descrição das obrigações de fazer e/ou não fazer, de forma a contemplar as } \\
\text { circunstâncias de modo, tempo, lugar e outras. }\end{array}$ \\
\hline & Estabelecimento de prazo para o cumprimento das obrigações. \\
\hline & $\begin{array}{l}\text { Cominação, nos casos de não cumprimento das obrigações pactuadas, de eventual } \\
\text { sanção (multa) a ser aplicada. }\end{array}$ \\
\hline & Demonstração de resolutividade e eficácia do ponto de vista jurídico e social. \\
\hline & Participação social, por intermédio de pessoas ou entes representativos. \\
\hline & $\begin{array}{l}\text { Ampla publicidade dos termos de ajustamento de conduta do ponto de vista de } \\
\text { sua elaboração e dos seus resultados para a sociedade. }\end{array}$ \\
\hline & $\begin{array}{l}\text { Efetividade na fiscalização e adoção de providências, no sentido de execução de } \\
\text { termos de ajustamento eventualmente descumpridos. }\end{array}$ \\
\hline \multirow{3}{*}{ Recomendações } & Apresentação dos devidos fundamentos constitucionais ou legais. \\
\hline & $\begin{array}{c}\text { Demonstração da utilidade social, principalmente por expressar a adequada } \\
\text { defesa dos direitos e/ou garantias constitucionais fundamentais, individuais ou } \\
\text { coletivas. }\end{array}$ \\
\hline & $\begin{array}{c}\text { Efetividade na fiscalização sobre o acatamento das recomendações expedidas e } \\
\text { adoção das providências eventualmente cabíveis na hipótese de descumprimento } \\
\text { e manutenção do ilícito. }\end{array}$ \\
\hline
\end{tabular}

Quadro 1: Fatores a serem considerados nas atividades correicionais. Elaborado pelo autor. Fonte: CNMP, $2016 \mathrm{~b}$.

\subsection{A estrutura orgânica do Ministério Público Federal na temática saúde}

No âmbito do Ministério Público Federal, figuram como órgãos de coordenação, revisão e integração da atuação funcional dos membros da Instituição a Procuradoria Federal dos Direitos do Cidadão (PFDC) e as Câmaras de Coordenação e Revisão (CCRs), cujos fundamentos encontram previsão nos arts. 39 e 40 e 43, IV, da Lei Complementar no 75/939, respectivamente (BRASIL, 1993).

As CCRs do Ministério Público Federal são os órgãos setoriais que coordenam, integram e revisam o exercício funcional dos membros da Instituição e são organizadas por função ou por matéria.

A Lei Orgânica do Ministério Público da União (LC no 75/1993, art. 62) define as competências das CCRs, dentre as quais destacam-se: a) promover a integração e a coordenação 
dos órgãos institucionais que atuem em ofícios ligados ao setor de sua competência, observado o princípio da independência funcional; b) encaminhar informações técnico-jurídicas aos órgãos institucionais que atuem em seu setor; c) resolver sobre a distribuição especial de feitos que, por sua contínua reiteração, devam receber tratamento uniforme; d) resolver sobre a distribuição especial de inquéritos, feitos e procedimentos, quando a matéria, por sua natureza ou relevância, assim o exigir; e) decidir os conflitos de atribuições entre os órgãos do Ministério Público Federal (BRASIL, 1993).

\section{INSTRUMENTOS EXTRAJUDICIAIS DO MINISTÉRIO PÚBLICO}

Um dos instrumentos de atuação extrajudicial e que também consiste no cerne do objeto do presente trabalho é o expediente denominado recomendação legal. Por meio do normativo em análise (Resolução no 87/2010), a recomendação consiste em um dos mecanismos pelo qual o órgão do Ministério Público, no exercício das atribuições do art. 129, II e III, da Constituição Federal, de ofício ou mediante provocação, poderá expedir aos responsáveis indicados nos autos de inquérito civil ou procedimento administrativo encaminhamentos para que sejam observados os direitos e interesses que lhe incumba defender. Tais atos, por determinação da Resolução, devem ser publicados no portal eletrônico do MPF.

A recomendação conterá o prazo para o seu cumprimento, bem como indicará as medidas que deverão ser adotadas no caso do seu não cumprimento. No caso de a recomendação não ser atendida, conforme o caso, é facultado ao Ministério Público instaurar inquérito civil, celebrar o compromisso de ajustamento de conduta ou promover a ação civil competente.

Destaque-se que podem ocorrer situações em que a expedição de recomendação não seja suficiente para corrigir a irregularidade detectada. Neste caso, ainda é possível ao membro oficiante propor a celebração de termo de ajustamento de conduta ou ingressar em juízo com a propositura de ação civil pública.

Quanto ao compromisso de ajustamento de conduta, Magalhães (2013) pontua que é instrumento disponível aos órgãos públicos que possuam a legitimidade à propositura da ação civil pública e por meio do qual no campo extrajudicial "[...] pode-se obter do investigado a obrigação de se ajustar à lei, mediante prevenção, cessação da conduta lesiva e reparação do dano".

Destaca-se, também, que se trata de eficiente instrumento à disposição do Ministério Público e demais colegitimados, viabilizando, de forma extrajudicial e preventiva, seja o investigado compelido a providenciar o necessário para a reparação do dano, cessação da conduta e prevenção, evitando-se, assim, alguns inconvenientes do acionamento do Judiciário, sobretudo a demora do processo judicial de conhecimento necessário para formalização do título executivo (MAGALHÃES, 2013).

Desde que cumpridas as suas formalidades, o compromisso de ajustamento de conduta transforma-se em título executivo extrajudicial, podendo ser exigido judicialmente no caso de descumprimento de suas cláusulas pelo causador do dano. Embora não obrigatório, ou seja, não imposto ao Ministério Público como condição para o ajuizamento de ação civil pública, muitos autores defendem que a utilização prévia desse instituto é uma boa prática, que privilegia o princípio da eficiência administrativa prevista no art. 37 da Constituição da República, assim como o acesso à Justiça mediante solução negocial de conflitos. 


\section{METODOLOGIA}

Foram utilizadas fontes primárias constantes em documentos oficiais, como relatórios, anuários, leis, regulamentos e informações oriundos do CNMP, da administração superior do MPF, bem como dos órgãos de coordenação e revisão (1a CCR e PFDC), com o objetivo de reunir elementos para demonstrar como o Ministério Público Brasileiro, mais especificamente o Ministério Público Federal, tem se posicionado sobre a sua atuação resolutiva, bem como sobre as medidas tendentes a promover o fortalecimento e a efetividade no campo extrajudicial.

Efetuou-se, também, pesquisa na base de dados do Sistema Integrado de Informações Institucionais do Ministério Público Federal -Sistema Único ${ }^{4}$, utilizando-se como apoio à pesquisa a ferramenta de busca denominada Sistema APTUS 5 , no sentido de extrair dados de identificação de todos os TACs e recomendações decorrentes de procedimentos preparatórios e de inquéritos civis públicos expedidos e registrados no período da pesquisa (janeiro de 2013 a dezembro de 2015), disponíveis na referida base de dados informatizada. Na consulta foram extraídos os seguintes dados de identificação dos instrumentos: órgão revisor vinculado, procedimento originário, resumo do assunto, data do cadastro, membro responsável, registro do TAC ou da Recomendação e a data do respectivo expediente.

Na extração dos dados do Sistema, utilizou-se como critérios o recorte temático referente às demandas sobre a saúde pública no âmbito de atuação da 1 a Câmara de Coordenação e Revisão e da Procuradoria Federal dos Direitos do Cidadão; como recorte temporal, fixou-se o período de janeiro de 2013 a dezembro de 2015. Os parâmetros da pesquisa foram, quanto ao gênero, "Documento"; a fixação dos períodos "o1/o1/2013 a 31/12/2013", "01/o1/2014 a 31/12/2014" e "01/01/2015 a 31/12/2015"; a classificação do documento, "Recomendação"; e termo de pesquisa, "saúde". O processo foi repetido para os Termos de Ajustamento de Conduta, alterando-se a expressão apenas no campo "classificação do documento".

Necessário esclarecer que, para o alinhamento à terminologia institucional utilizada para a identificação dos trabalhos realizados pelo MPF, foram adotados os parâmetros definidos na tabela de assuntos do CNMP. ${ }^{6}$

Em razão do grande número de Recomendações expedidas, por questões relacionadas a limitações informacionais do Sistema Único, que ainda não dispõe de recursos suficientes para se verificar o cumprimento desses expedientes, utilizou-se do critério de análise quantitativa para demonstrar o volume de recomendações expedidas pelo MPF em seu conjunto e em cada Unidade da Federação, bem como o montante correspondente à esfera de atribuição de cada um dos órgãos de coordenação e revisão (PFDC e $1^{\text {a }}$ CCR). Os dados também serviram para demonstrar a evolução, ano a ano, dessa ferramenta, de modo a poder aferir a intensidade e o desenvolvimento da atuação resolutiva institucional em âmbito nacional.

Por outro lado, relativamente aos resultados dos TACs, dado o montante apurado, optou-se por realizar a avaliação qualitativa dos instrumentos, de modo a aferir a efetividade da Instituição quanto ao manejo desse instrumento de atuação extrajudicial. Diante do fato das limitações já declinadas em relação ao Sistema Único, impossibilitando o fornecimento

4 Sistema que controla a gestão do fluxo processual na Instituição (Sistema Único). Criado para agilizar e unificar o trâmite de documentos judiciais e administrativos, ele permite a integração nacional do MPF de forma transparente, além de dar celeridade e segurança à tramitação de processos.

5 Aplicativo de pesquisa textual unificada e simplificada, que tem por objetivo realizar pesquisas de processos, procedimentos, peças e manifestações diversas na base de dados do Sistema Único, exceto os casos sigilosos. Possibilita a utilização de filtros, mediante a fixação de parâmetros para busca, bem como salvar os resultados.

6 As Tabelas Unificadas foram criadas pela Resolução no 63/2010 do Conselho Nacional do Ministério Público -CNMP, visando à padronização e uniformização das terminologias utilizadas pelas unidades do Ministério Público, permitindo conhecer o trabalho realizado pelos seus diversos ramos. Fonte:http://www.cnmp.mp.br/tabelasunificadas/apresentaaoo.

6 As Tabelas Unificadas foram criadas pela Resolução no 63/2010 do Conselho Nacional do Ministério Público -CNMP, visando à padronização e uniformização das terminologias utilizadas pelas unidades do Ministério Público, permitindo conhecer o trabalho realizado pelos seus diversos ramos. Fonte:http://www.cnmp.mp.br/tabelasunificadas/apresentaaoo. 
direto do resultado das avenças materializadas nos TACs, foi necessário adotar a técnica da observação direta extensiva, mediante a utilização de questionário direcionado aos responsáveis pela área de apoio jurídico e documentação das Unidades do MPF nos Estados e nos Municípios. ${ }^{7} \mathrm{O}$ questionário foi estruturado em três perguntas a saber: (I) o TAC encontrase vigente?; (II) as obrigações constantes do TAC foram cumpridas total ou parcialmente?; (III) a questão envolvida no TAC foi objeto de judicialização? Se positivo, indicar o número do processo judicial correspondente.

Os resultados obtidos da consulta ao Sistema no que concerne aos TACs foram segregados por Unidade da Federação e os objetos correspondentes descritos de forma sintética. A partir da resposta aos questionários, as informações foram sendo organizadas de forma individualizada e vinculada a cada instrumento, de modo que se tornou possível estabelecer a relação dos termos cumpridos e dos termos violados, bem como identificar a quantidade de judicialização das questões até então acordadas.

\section{ANÁLISE E DISCUSSÃO DOS RESULTADOS}

Realizada a pesquisa na base de dados do Sistema Único, buscou-se o levantamento da quantidade de procedimentos instaurados pelo Ministério Público Federal na temática Saúde Pública. Procurou-se separar os procedimentos que geraram termos de ajustamento de conduta, recomendações e os que não constam nenhum dos dois instrumentos. Quanto aos procedimentos que geraram termos de ajustamento de conduta, apurou-se que foram celebrados 75 instrumentos, dos quais 54 contém matérias vinculadas à PFDC e 21, à $\mathbf{1}^{\underline{a}} \mathrm{CCR}^{8}$.

No que se refere aos procedimentos que levaram a recomendações, a pesquisa retornou o total de 2.331, dos quais 1.328 contém matérias vinculadas à PFDC e 1.003, à $1^{\underline{a}}$ CCR. Relativamente à quantidade de procedimentos que não originaram termos de ajustamento de conduta ou recomendações, extrai-se que foram instaurados 8.774, dos quais 7.012 contém matérias vinculadas à PFDC e 1.762 à $1^{\underline{a}}$ CCR.

A Tabela 1 a seguir demonstra o quantitativo de Termos de Ajustamento de Conduta, de Recomendações e de feitos extrajudiciais cujas matérias referem-se à saúde pública que estão vinculados às esferas de atribuições da PFDC e da $1^{\underline{a}}$ CCR.

Tabela 1: Procedimentos por Órgão de Coordenação e Revisão

\begin{tabular}{c|c|c|c}
\hline Órgão & Procedimentos com TAC & $\begin{array}{c}\text { Procedimentos com } \\
\text { Recomendações }\end{array}$ & $\begin{array}{c}\text { Procedimentos sem TAC e } \\
\text { sem Recomendaçóes }\end{array}$ \\
\hline PFDC & $54(72 \%)$ & $1328(57 \%)$ & $7012(80 \%)$ \\
\hline $1^{a-C C R}$ & $21(28 \%)$ & $1003(43 \%)$ & $1762(20 \%)$ \\
\hline Total & $75(100 \%)$ & $2331(100 \%)$ & $8774(100 \%)$ \\
\hline
\end{tabular}

Elaborada pelo autor. Fonte: Sistema Único de Informações.

\footnotetext{
7 Conforme dispõe o art. 268 do RIA do MPF, incumbe aos Coordenadores e Subcoordenadores Jurídicos e de Documentação, "coordenar, organizar e monitorar as atividades pertinentes ao registro, à distribuição e à movimentação de procedimentos extrajudiciais", bem como "coordenar e supervisionar a execução das atividades pertinentes à prestação de informações ao público" (BRASIL, 2016a).

8 Por questões de espaço, este artigo se limitou a apresentar parte dos resultados das análises.
} 


\subsection{A pesquisa dos Termos de Ajustamento de Conduta}

Numa perspectiva mais detalhada sobre os Termos de Ajustamento de Conduta, temse que, do total de 75 instrumentos, nove foram celebrados em 2013; 54 em 2014; e 12 em 2015. Deste total, 56 decorreram de Inquéritos Civis; 02 de procedimentos administrativos; e 17 de procedimentos preparatórios.

Cabe esclarecer que o acentuado número de Termos celebrados em 2014, em comparação aos dos demais anos, deve-se em razão da forte atuação do Ministério Público Federal em Alagoas quanto à verificação do descumprimento da jornada de trabalho de 40 horas semanais por parte de profissionais de saúde lotados nos Programas de Saúde da Família -PSF. Apenas nessa linha de atuação, foram expedidos 25 termos, abrangendo diversos municípios alagoanos. Esta questão será tratada adiante, de forma mais detida.

A atuação nessa perspectiva -qual seja, a celebração de Termos de Ajustamento de Conduta referentes ao tema saúde -ocorreu nas Unidades do MPF em Alagoas; Amapá; Bahia (Procuradoria da República em Jequié e em Eunápolis); Ceará (Procuradoria da República em Juazeiro do Norte); Distrito Federal; Goiás; Espírito Santo (Procuradoria da República em Colatina); Mato Grosso do Sul (Procuradoria da República em Corumbá e em Coxim); Paraíba (Procuradoria da República em Sousa); Pernambuco (Procuradoria da República em Caruaru); Rio Grande do Sul (Procuradoria da República em Cruz Alta); Rio de Janeiro (Procuradoria da República em Petrópolis e em São João do Meriti); Roraima; Rio Grande do Norte (Procuradoria da República em Caicó); e São Paulo (Procuradoria da República em Campinas, em Itapeva, em Ribeirão Preto, em Registro e em Santos).

Um aspecto relevante que deve ser ressaltado é quanto à atuação dos membros nas unidades do MPF localizadas nos municípios (PRMs) em relação ao total de TACs celebrados no período. Dos instrumentos levantados, observa-se que 39 são oriundos dessas unidades municipais, ou seja, mais de $50 \%$ do universo apurado.

Em média, verificou-se que, entre a data do cadastro do procedimento e a celebração dos termos de ajustamento de conduta, decorreram 853 dias ou aproximadamente 28,4 meses. O menor prazo apurado foi de cinco dias (Termo de Ajustamento de Conduta no 4/2015-Termo de Compromisso -LLO/PRDF/MPF) e o maior de 2890 dias (Termo de Ajustamento de Conduta 2015 -PR-DF-oooo6351/2015).

As questões atinentes a recursos materiais consistiram em irregularidades relacionadas à paralisação de obras de unidade de saúde; insuficiência de disponibilização de transporte de pacientes para realização de hemodiálise; ausência de aparelhagem (máquina peritoneal) para pacientes renais crônicos; fechamento de Unidade de Terapia Intensiva (UTI); funcionamento de Unidade de Pronto Atendimento (UPA 24h); sobrecarga de capacidade de hospital e necessidade de estruturação de rede própria de atendimento à saúde por parte de município; locação de equipamentos e insumos de hemodiálise; e implantação de central de regulação ambulatorial.

Os demais pontos referentes à gestão dizem respeito à irregularidade no atendimento de serviços de saúde; ausência de fornecimento aos usuários de certidão de não atendimento no sistema SUS; ausência de alimentação de banco de preços na aquisição de insumos de saúde; perecimento e descarte irregular de medicamentos; condições precárias de armazenamento, dispensação e acesso a medicamentos; atraso no repasse da verba do SUS para a rede privada conveniada;irregularidades na prestação de assistência médica aos militares e seus dependentes; e fiscalização de cumprimento de meta de redução da taxa de mortalidade materna.

Cabe destacar, ainda, o objeto do Inquérito Civil no 1.24.00o.001421/2014-74, que consiste em induzir a adoção pelo poder público de medidas tendentes a assegurar o acesso 
a medicações derivadas da planta Cannabis Sativa por parte de pacientes portadores de enfermidades neurológicas convulsionantes e incapacitantes.

No Estado de Alagoas, a pesquisa retornou o total de 26 TACs celebrados. No que diz respeito aos vinte e cinco primeiros, os objetos versam sobre a delimitação da obrigação dos profissionais da saúde em trabalhar no Programa de Saúde da Família -PSF no cumprimento da jornada de 40 horas semanais de trabalho, bem como estabelecer as condições para que prefeituras municipais garantam o devido cumprimento da carga horária por parte desses profissionais. Quanto ao instrumento PR-AL-0oo16371/2016 (celebrado em 2015), o objeto consiste na regularização do atendimento e dos serviços prestados pelo Hospital Carvalho Beltrão.

No Estado do Amapá, a pesquisa apontou a celebração do TAC no 1/2014 (PRAP-o0o19192/2014). O objeto do instrumento consiste na tomada de compromisso do Estado do Amapá, da União, da Secretaria de Saúde do Estado, do Hospital das Clínicas Alberto Lima, da Clínica de Nefrologia do Hospital e das Clínicas Alberto Lima no sentido de adequar o Serviço de Nefrologia do Hospital de Clínicas Dr. Alberto Lima -HCAL às determinações relacionadas pelo Serviço de Auditoria do SUS (Relatório Final da Auditoria no 13381) e pela Unidade de Vigilância Sanitária em Serviços relacionados à Saúde (Relatório de Inspeção n.o 059/2013 e Notificação no 119/2013 UVSRS/DIVISA).

No Estado da Bahia foram identificados o TAC no 01/2015 (PRM-TXF-BA-ooooo528/2015) e o TAC PRM-JQE-BA-oooo3176/2014. O TAC no 01/2015, firmado com o Município de Teixeira de Freitas, teve como objeto coibir a contratação e a manutenção de empregados no quadro de pessoal da área da saúde, especialmente os vinculados ao SAMU, sem observar a regra do prévio concurso público, conforme previsto no art. 37, inciso II, da CF/88.

O segundo instrumento (PRM-JQE-BA-0oo03176/2014) promovido pelo Ministério Público do Estado da Bahia e pelo MPF, tendo como compromissário o Município de Jequié, cujo objetivo central da avença consiste na viabilização da contratação de 20 leitos de suporte com recurso diverso do já previsto na dotação orçamentária da Secretaria Municipal de Saúde.

Não obstante o encaminhamento do questionário à unidade responsável pelo TAC no 01/2015 (PRM-TXF-BA-oooo0528/2015) e as reiterações da solicitação, até o fechamento da pesquisa não se obteve resposta da Unidade. Não foi possível, portanto, saber o resultado, restando o trabalho prejudicado neste ponto. No que tange ao TAC (PRM-JQEBA-00003176/2014), encontra-se esse vigente, na data da pesquisa; as obrigações não foram cumpridas e as questões foram objeto de judicialização.

No Ceará consta o TAC PRM-JZN-CE-oooo9318/2013, celebrado pelo MPF com o Município de Juazeiro do Norte. O objeto do instrumento consiste na viabilização pelo Município do adequado funcionamento da UTI Neonatal e a Unidade de Cuidados Intermediários (Berçário de médio risco) do Hospital Municipal São Lucas. Devendo, para tanto, ser realizada a aquisição de diversos equipamentos e materiais hospitalares em quantidade suficiente para atender a oito leitos de UTI e 14 leitos de berçário de médio risco, tais como monitores cardíacos, bombas de infusão, equipamentos de ar comprimido e oxigênio, incubadoras, circuito respirador etc.

Além da questão do funcionamento da UTI Neonatal e da Unidade de Cuidados Intermediários, o Município também se comprometeu a corrigir as não conformidades apontadas pela Secretaria de Estado de Saúde do Ceará, nas seguintes unidades do Hospital Municipal São Lucas: Unidade de Cuidados Intermediários Neonatal; no Centro Cirúrgico; na Unidade de Internação; na Central de Material Esterilizado; na Sala de pré-parto; na cozinha e no Banco de Leite do Hospital Municipal São Lucas.

No Distrito Federal, a pesquisa indicou os TACs no 4/2015 (PR-DF-00049513/2015) e PR-DF-oooo6351/2015. O primeiro instrumento tem por finalidade impedir o fechamento 
iminente das unidades de terapia intensiva adulto e neonatal do Hospital Universitário de Brasília -HUB, evitar a produção de danos ainda maiores à saúde pública (rede pública de saúde do Distrito Federal) e prevenir responsabilidades cíveis e administrativas. Para tanto, estabelece autorização para que a EBSERH -Empresa Brasileira de Serviços Hospitalares e o HUB efetuem a contratação de 19 profissionais da área médica para atender necessidades emergenciais da UTI adulto, UTI neonatal e urgência/emergência, por meio de processo seletivo simplificado.

Quanto ao TAC registro PR-DF-oooo6351/2015, tem como escopo regulamentar a alocação de servidores cedidos pela FUNASA à Secretaria de Estado de Saúde do Distrito Federal, para atuar no combate às endemias e zoonoses. Em resposta aos questionários, foi informado que o TAC envolvendo o HUB encontra-se arquivado e que as obrigações constantes foram revogadas, sem que a questão houve sido objeto de judicialização. Já em relação ao TAC referente à alocação de servidores, não se obteve resposta ao questionário, até o fechamento desta pesquisa, restando prejudicada a análise.

Em Goiás, verificou-se a celebração do TAC no 2/2014 (PR-GO-ooo47651/2014). O instrumento tem como objeto central a recomposição dos quadros de enfermeiros do Hospital Araújo Jorge/Associação de Combate ao Câncer em Goiás -ACCG. Apurou-se, também, a celebração do documento denominado TAC n¹/2013 com o registro PR-GO-ooo10120/2013 que, em verdade, conforme esclarecimentos prestados pelo setor responsável da PR/GO, trata-se de Termo de Cooperação Técnica e Operacional no 1/2013, firmado entre o MPF e o CREMEGO, estando, portanto, fora do escopo do presente estudo.

No TAC no 2/2014 (PR-GO-ooo47651/2014), celebrado entre o MPF, o Conselho Regional de Enfermagem de Goiás -COREN/GO e o Hospital Araújo Jorge/Associação de Combate ao Câncer em Goiás -ACCG, este último assumiu o compromisso de efetuar a contratação de 31 enfermeiros "[...] com vistas à adequação quanti-qualitativa do quadro de enfermagem para uma assistência segura ao paciente e consequente melhoria da saúde do trabalhador no Hospital Araújo Jorge/ACCG”.

Também restou acordado que o compromissário não impediria a atuação fiscalizatória do COREN/GO, "[...] fornecendo as informações necessárias e franqueando o acesso às instalações do Hospital, a fim de que os fiscais possam cumprir com suas funções de fiscalização, desde que somente no âmbito da atuação dos profissionais de Enfermagem e conforme determina as leis e normas legais vigentes".

Como medidas concretas para a execução do objeto acordado, os municípios se comprometeram a providenciar a instalação e o regular funcionamento de registro eletrônico de frequência dos servidores públicos vinculados ao Sistema Único de Saúde; a disponibilizar, em local visível das salas de recepção de todas as unidades públicas de saúde, quadros que informem ao usuário, de forma clara e objetiva, o nome, especialidade e horário de início e de término da jornada de trabalho de todos os médicos, odontólogos, enfermeiros e demais profissionais da área de saúde em exercício na unidade; e disponibilizar nas unidades de saúde, para consulta de qualquer cidadão, o registro de frequência dos profissionais que ocupem cargos públicos vinculados ao SUS.

No que se refere às aquisições de insumos de saúde, assumiram a obrigação de providenciar a inserção e a atualização periódica dos dados correspondentes no Banco de Preços em Saúde, assim como a utilizar esse banco de dados como fonte de consulta para orientar os processos licitatórios das aquisições de insumos.

No aspecto referente ao cumprimento das avenças, constatou-se que 39 TACs tiveram as obrigações estabelecidas efetivamente cumpridas na sua integralidade; 12 cumpridas parcialmente; seis tiveram os acordos descumpridos totalmente e três tiveram respostas 
diversas que não se enquadravam em nenhum dos três primeiros parâmetros. Todos os acordos descumpridos totalmente e um parcialmente foram objeto de judicialização.

Para efeito de verificação e estabelecimento de um índice de efetividade da atuação extrajudicial do Ministério Público Federal, quanto aos TACs, propõe-se que para os casos em que as obrigações foram cumpridas totalmente, seja atribuído peso um e para as cumpridas parcialmente, peso o, 5 e, naturalmente, para as cujo descumprimento foi total, o. Como foram obtidas respostas sobre o resultado do cumprimento de 57 (cinquenta e sete) TACs, o cálculo será feito sobre este montante. $\mathrm{O}$ indicador seria calculado da seguinte forma: TACs cumpridos totalmente $\mathrm{x} 1$ + TACs cumpridos parcialmente $\mathrm{x} 0,5 /$ Total de TACs cujos resultados foram validamente apurados.

\section{TAC CT $\times 1+$ TAC CP $\times 0,5 \times 100$ \\ TACs VA}

Assim, para os TACs cumpridos totalmente tem-se 39 (trinta e nove) pontos e para os TACs cumpridos parcialmente, o6 (seis) pontos, totalizando 45 (quarenta e cinco) pontos. Assim, dentro do universo pesquisado, a atuação ministerial indicou um percentual de $78,94 \%$ de aproveitamento relativamente à sua atuação extrajudicial.

Logo, o baixo nível de judicialização dos Termos de Ajustamento de Conduta sugerem que a utilização desse instrumento extrajudicial parece ter potencial efetivo para reduzir os níveis de judicialização associados à atuação do Ministério Público Federal e, portanto, de reforçar seu caráter resolutivo.

\subsection{A pesquisa das Recomendações}

Especificamente sobre as Recomendações, levantou-se que do total de 2.331 documentos expedidos, 296 foram em 2013; 1.108 em 2014; e 927 em 2015. Deste total, 1.487 decorreram de Inquéritos Civis; 697 de Procedimentos Administrativos; 137 de Procedimentos Preparatórios e 10 de Notícias de Fato.

As Unidades do MPF que expediram Recomendações no período estão localizadas em todas as Unidades da Federação.

Um ponto a ser destacado refere-se à participação das PRMs. As unidades localizadas nos Municípios expediram 957 Recomendações, representando um percentual de $41 \%$ de participação em relação ao total do MPF.

A partir da planilha Excel contendo os dados dos procedimentos, utilizando-se da funcionalidade localizar, identificou-se, no campo resumo, as matérias de maior incidência da atuação institucional, que foram objeto das Recomendações expedidas. Sendo elas:

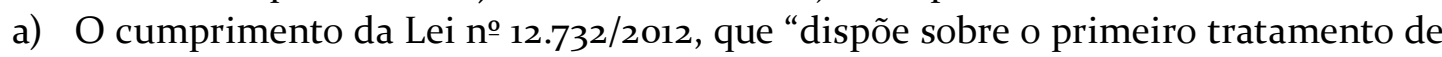
paciente com neoplasia maligna comprovada e estabelece prazo para seu início" e a implementação do Sistema de Informação do Câncer (SISCAN), contendo 177 registros;

b) Fornecimento de certidões aos usuários que não tenham sido atendidos pelo Sistema Único de Saúde, à publicidade das aquisições de insumos de saúde, ao registro eletrônico de frequência dos servidores públicos vinculados ao Sistema Único de Saúde, com o registo de 378 recomendações; 
c) Exigência da instalação de instrumentos que permitam o controle social do horário de atendimento dos profissionais prestadores de serviços médico e odontológico, com 113 recomendações expedidas;

d) Adoção de medidas para fomentar o correto atendimento e tratamento às pessoas possivelmente infectadas pelo vírus Influenza $\mathrm{A}\left(\mathrm{H}_{1} \mathrm{~N}_{1}\right)$ no âmbito do Sistema Público de Saúde, com 224 recomendações expedidas; e

e) Cumprimento dos "Objetivos de Desenvolvimento do Milênio, do Programa das Nações Unidas para o Desenvolvimento -ODM-5 -"melhorar a saúde materna”, da qual o Brasil foi signatário, tendo como uma das metas "reduzir em três quartos, entre 1990 e 2015, a taxa de mortalidade materna", bem como acompanhar o cumprimento do "Programa Rede Cegonha" (25 registros).

A partir da função "aleatório" do aplicativo Excel, das 2330 Recomendações, foram selecionadas 300 como amostragem e, a partir dessas, verificou-se que entre a data do cadastro do procedimento e a expedição da Recomendação, decorreram, em média, 237 dias ou, aproximadamente, 7,9 meses. O menor prazo apurado foi de um dia (Recomendação no 16/2015 -PRM-PGN-PA-oooo1164/2015) e o maior de 1405 dias (Recomendação no 107/2013 -PRSC-00020167/2013).

A expressiva participação dos órgãos que atuam nas PRMs no que se refere à expedição de Recomendações ( $41 \%$ do total das emitidas pelo MPF) demonstra, além do caráter nacional da Instituição, a sua aproximação da sociedade e, ainda, levam a entender que o processo de interiorização das Unidades do MPF, iniciado na década de 2000, tem reforçado a ideia de que a presença local é importante para o desempenho da missão institucional, notadamente no que tange à defesa do direito à saúde, onde a pesquisa demonstrou que as mazelas da sociedade e as deficiências da gestão geralmente ocorrem em locais distantes das capitais e dos grandes centros urbanos.

Muito embora não se tenha verificado um prazo razoavelmente uniforme entre a instauração de um procedimento e a expedição de uma recomendação, da média de 300 expedientes analisados, constatou-se um prazo de 237 dias ou, aproximadamente, 7,9 meses, o que ainda assim se revela vantajoso, considerando o tempo que se leva para se processar uma demanda no Poder Judiciário de 1,5 ano na fase de conhecimento e 4,3 anos na fase de execução (CNJ, 2016, p. 7o).

Tabela 2: Instrumentos extrajudiciais celebrados/expedidos por região do país

\begin{tabular}{c|c|c|c|c}
\hline Região & TAC & Recomendação & Total & $\%$ \\
\hline Norte & 3 & 505 & 508 & $21,1 \%$ \\
\hline Nordeste & 48 & 384 & 432 & $18,0 \%$ \\
\hline Sul & 14 & 452 & 466 & $19,4 \%$ \\
\hline Sudeste & 1 & 412 & 413 & $17,2 \%$ \\
\hline Centro-Oeste & 5 & 578 & 583 & $24,3 \%$ \\
\hline Brasil & 71 & 2331 & 2402 & $100,0 \%$ \\
\hline
\end{tabular}

Elaborada pelo autor. Fonte: Sistema Único de Informações. 
Por fim, não é possível avaliar se a via resolutiva é a preferida do MPF ou se, ao menos, existe a busca crescente por instrumentos extrajudiciais. Os dados levantados na pesquisa demonstram uma certa instabilidade no número de TACs celebrados e Recomendações expedidas. Não se vislumbra um "comportamento" que indique o aumento da atuação resolutiva -isso pode ser extraído da Tabela 2 -sendo necessário para uma análise mais ampla o levantamento em relação a período de observação maior do que o estabelecido nesta pesquisa que abrangesse, inclusive, os efeitos da Carta de Brasília.

Muito embora não se tenha realizado uma comparação entre a atuação demandista e a resolutiva no aspecto empírico, procurou-se demonstrar ao longo do trabalho que a Instituição tem buscado a maior eficiência da sua atuação, reconhecendo a necessidade de ampliação da atuação extrajudicial para dirimir os conflitos em todas as suas áreas, de forma preventiva, proativa e resolutiva.

Dentro das limitações antes colocadas, acredita-se que foi possível responder a questão sobre em que medida os TACs celebrados pelo MPF tem evitado a judicialização das questões que aportaram à Instituição (item 1.3-Objetivo), tendo sido demonstrado que resultou no aproveitamento de $78,94 \%$ dos instrumentos celebrados, conforme o método de apuração proposto.

Há também outro aspecto observado que convém ressaltar. Refere-se à verificação no presente trabalho de atuações quase sempre pontuais do MPF por meio dos TACs. Alguns casos voltaram-se para pequenos grupos ou áreas geográficas. Isso decorre dentre outros fatores, da delimitação da esfera de atribuição própria do órgão oficiante, como é o caso do membro que atua numa determinada municipalidade ou grupo de municípios, por exemplo. A menos que a ação faça parte da atuação coordenada da PFDC e da $1^{\underline{a}}$ CCR, quando a intervenção não é sistêmica, há o risco de que ela desequilibre o sistema da política pública.

\section{CONCLUSÃO}

O Sistema Único de Saúde, a despeito dos objetivos e diretrizes preconizados na Constituição Federal de 1988, experimentou avanços significativos ao longo dos trinta anos de promulgação da Carta Magna, mas ainda não cumpriu o seu papel fundamental de fazer com que o Estado Brasileiro promova as condições indispensáveis para o pleno exercício do direito à saúde.

É no processo de redemocratização do país em 1988 que surge o Ministério Público como instituição vocacionada à defesa dos interesses da sociedade, revestido de garantias e prerrogativas para exercer esse mister de forma ampla, sendo-lhe conferidos, inclusive, instrumentos de cunho extrajudicial para tanto. É nesse novo contorno que surge a concepção de um Ministério Público também apto a buscar as soluções para os conflitos de interesses não apenas na via judicial.

Restou evidenciado na revisão bibliográfica a consolidação do novo perfil do Ministério Público resolutivo, cada vez mais distante do traço demandista que o caracterizava até o advento da Constituição de 1988, ressaindo, assim, como ator de relevante destaque no sentido de influenciar a concepção, o aprimoramento e a execução das políticas públicas de saúde.

Embora não se possa afirmar que a Instituição tem atuado mais na esfera extrajudicial em comparação com a judicial, por falta elementos para tanto, o que se buscou enfatizar foi que o Ministério Público Brasileiro e o MPF vêm proclamando diretrizes e adotando estratégias no sentido da atuação resolutiva. Isso restou 
demonstrado quando foram tratadas as políticas desenvolvidas pelo CNMP, a exemplo da Carta de Brasília e da Política Nacional de Fomento à Atuação Resolutiva do Ministério Público Brasileiro.

\section{REFERÊNCIAS}

ALMEIDA, G. A. Direitos fundamentais e os principais fatores de legitimação socialdo Ministério Público no neoconstitucionalismo. In: ALMEIDA, G. A. (Coord.). Teoria Geral do Ministério Público. Belo Horizonte: Del Rey, 2013. p. 1-82.

BRASIL. Constituição da República Federativa do Brasil de 1988. Disponível em: <http:// www.planalto.gov.br/ccivil_03/Constituicao/Constituicao.htm>. Acesso em: abr. 2017.

Constituição (1988). Emenda Constitucional no 95, de 15 de dezembro de 2016. Altera o Ato das Disposições Constitucionais Transitórias, para instituir o Novo Regime Fiscal, e dá outras providências. Disponível em: <http://www.planalto.gov.br/ccivil_o3/constituicao/ emendas/emc/emc95.htm>. Acesso em: mar. 2018.

Lei Complementar no 75, de 20 de maio de 1993. Dispõe sobre a organização, as atribuições e o estatuto do Ministério Público da União. Disponível em: <http://www.planalto. gov.br/ccivil_03/leis/lcp/lcp75.htm>. Acesso em: set. 2017.

Conselho Superior do Ministério Público Federal. Resolução no 87, de 6 de abril de 2010b. Regulamenta, no âmbito do Ministério Público Federal, a instauração e tramitação do Inquérito Civil (art. $6^{\circ}$, VII, da Lei Complementar $n^{\circ} 75 / 93$ e art. $8^{\circ}$, $\S 1^{\circ}$, da Lei $n^{\circ} 7 \cdot 347 / 85$ ). Disponível em: <http://bibliotecadigital.mpf.mp.br/bdmpf/bitstream/handle/11549/37227/ RES_CSMPF_2010_87.pdf?sequence=5\&isAllowed $=y>$. Acesso em: jul. 2017.

CASAGRANDE, C. Ministério Público e a judicialização da política: estudos de casos. Porto Alegre: Sérgio Antônio Fabris, 2008. 295 p.

CONSELHO NACIONAL DE JUSTIÇA (CNJ). Justiça em números 2016: ano base 2015/ Conselho Nacional de Justiça. Brasília: CNJ, 2016. Disponível em: <http://www.cnj.jus.br/files/ conteudo/arquivo/2016/10/b8f46be3dbbff344931a933579915488.pdf $>$. Acesso em: nov. 2017.

.Judicialização da saúde no Brasil: dados e experiência. Coords.: Felipe Dutra Asensi eRoseniPinheiro. Brasília:Conselho NacionaldeJustiça, 2015,142.p. Disponívelem:<http://www. cnj.jus.br/files/conteudo/destaques/arquivo/2015/o6/6781486daeforbc6ec8c1e491a565006. pdf $>$. Acesso em: jan. 2018.

CONSELHO NACIONAL DO MINISTÉRIO PÚBLICO (CNMP). Carta de Brasília, 2o17a. Disponível em: <http://www.cnmp.mp.br/portal/institucional/corregedoria/carta-debrasilia>. Acesso em: dez. 2017. 
Recomendação no 54, de 28 de março de 2017b. Dispõe sobre a Política Nacional de Fomento à Atuação Resolutiva do Ministério Público brasileiro. Disponível em: <http://www. cnmp.mp.br/portal/images/Recomendacoes/Recomenda\% ${ }_{3} \mathrm{C}_{3} \mathrm{~A}_{7} \% \mathrm{C}_{3} \% \mathrm{~A}_{30}$-054.pdf>. Acesso em: mai. 2017.

. Ministério Público: um retrato: dados de 2015, volume V/Conselho Nacional do Ministério Público. Brasília: CNMP, 2016a, 296 p. il, p. 217-220. Disponível em: <http://www. cnmp.mp.br/portal/images/MP_Um_retrato_WEB_FINAL.pdf>. Acesso em: dez. 2017.

Carta de Brasília: modernização do controle da atividade extrajurisdicional pelas corregedoriais do ministério público, 2016b. Disponível em: <http://www.cnmp.mp.br/portal/ images/Carta_de_Bras\%C3\%ADlia-2.pdf>. Acesso em: out. 2017.

Apresentada Proposta de resolução sobre a Política Nacional de Fomento à atuação resolutiva do MP, 2016c. Disponível em: <http://www.cnmp.mp.br/portal/todasas-noticias/9968-apresentada-proposta-de-resolucao-sobre-apolitica-nacional-de-fomento-aatuacao-resolutiva-do-mp>. Acesso em: abr. 2017.

Ministério Público: um retrato: dados de 2014, volume V/Conselho Nacional do Ministério Público. Brasília: CNMP, 2015a, 296 p. il, p. 217-220. Disponível em: <http:// www.cnmp.mp.br/portal/images/ANUARIO_UM_RETRATO_9_de_setembro_de_2014.pdf>. Acesso em: dez. 2017.

Comissão de Defesa dos Direitos Fundamentais e Comissão de Planejamento Estratégico. Projeto Incentivo da Autocomposição de Conflitos e Valorização da Atuação Extrajudicial, 2015b. Disponível em: <http://www.cnmp.mp.br/portal/images/Comissoes/ DireitosFundamentais/Arquivos/Projeto_AN1_-_Autocomposi $\% \mathrm{C}_{3} \% \mathrm{~A}_{7} \% \mathrm{C}_{3} \% \mathrm{~A}_{3} \mathrm{~A}_{-} \mathrm{e}_{-}$ Extrajudicial.pdf $>$. Acesso em: jul. 2017.

Ministério Público: um retrato: dados de 2013, volume V/Conselho Nacional do Ministério Público. Brasília: CNMP, 2014, 296 p. il, p. 217-220. Disponível em: <http://www. cnmp.mp.br/portal/images/stories/Destaques/Publicacoes/MP_Um_Retrato_2013.pdf>. Acesso em: dez. 2017.

INSTITUTO DE PESQUISAS ECONÔMICAS APLICADAS (IPEA). Evolução do gasto com medicamentos do Sistema Único de Saúde no período de 2010 a 2016. Texto para discussão / Instituto de Pesquisa Econômica Aplicada. Brasília : Rio de Janeiro: Ipea, 1990-, 2018. Disponível em: <http://repositorio.ipea.gov.br/bitstream/11058/8250/1/TD_2356.pdf>. Acesso em: fev. 2018.

JÚNIOR, João Cancio de Melo. Evolução constitucional do Ministério Público brasileiro. In: ALMEIDA, G. A. (Coord.). Teoria Geral do Ministério Público.Belo Horizonte: Del Rey, 2013. p. 83-110.

LIMA, Paulo César Vicente. Projetos Sociais -Novos instrumentos de atuação do Ministério Público. In: ALMEIDA, G. A. (Coord.). Teoria Geral do Ministério Público.Belo Horizonte: Del Rey, 2013. p. 464-490. 
MAGALHÃES, A. A. de A. Instrumentos de atuação extrajudicial do Ministério Público. In: SABELLA, W. P.; DAL POZZO, A. A. F.; FILHO J. E. B. (Coords.) Ministério Público: vinte e cinco anos do novo perfil constitucional. São Paulo: Malheiros, 2013. p. 678.

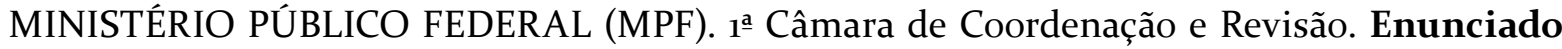
24.Ata da 289 a Sessão Ordináriarealizada em 18.5.2017 publicada em 12.7.2017. Disponível em: http://www.mpf.mp.br/atuacao-tematica/ccr1/atos-e-publicacoes/enunciados. Acesso em: mar. 2018.

Procuradoria Federal dos Direitos do Cidadão/Núcleo de Apoio Operacional. Voto no 3.715/2016/NAOP/PFDC/PRR3 ${ }^{\underline{a}}$ Região. Disponível no Sistema Único de Informações do MPF: registro PRR3 $3^{\mathrm{a}}-00020255 / 2016$.

Procuradoria Federal dos Direitos do Cidadão. Relatório de Atividades, 2o15a. Disponível em: <https://issuu.com/ccipfdc/docs/relatorio_de_atividades_pfdc_2015>. Acesso em: dez. 2017.

1aㅡ Câmara de Coordenação e Revisão Relatório de Atividades, 2015b. Disponível em:<http://www.mpf.mp.br/atuacao-tematica/ccr1/atos-e-publicacoes/relatorio-deatividades/relatorio-de-atividades-documentos/RelatorioAtividades2015.pdf $>$. Acesso em: set. 2017.

1ª̂ Câmara de Coordenação e Revisão. Informação no 3/2015/1aㅡ CCR, de 14 de maio de 2015c. Resposta ao Ofício 78/2015. Esclarecimentos quanto aos critérios a serem utilizados para definir a atribuição da Procuradoria Federal dos Direitos do Cidadão quando em aparente conflito com a 1 a Câmara de Coordenação e Revisão. Sistema Único de Informações. Disponível em: <https://portal.mpf.mp.br/aptus/unico?termoPesquisa=pgr-oo113753/2015>. Acesso em: jan. 2018.

Procuradoria Federal dos Direitos do Cidadão/Núcleo de Apoio Operacional. Voto

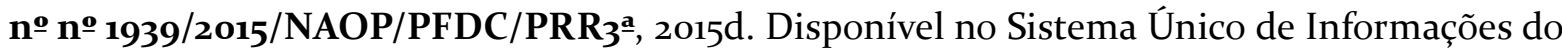
MPF: registro PRR3 $3^{\mathrm{a}}-00004671 / 2015$.

Procuradoria Federal dos Direitos do Cidadão. Relatório de Atividades, 2014a. Disponível em: <https://issuu.com/ccipfdc/docs/relatorio_pfdc_2014>. Acesso em: set. 2017.

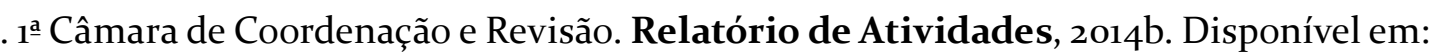
<http://www.mpf.mp.br/atuacao-tematica/ccr1/atos-e-publicacoes/relatorio-de-atividades/ relatorio-de-atividades-documentos/relatorio-de-atividades-2014.pdf $>$. Acesso em: set. 2017.

Procuradoria Federal dos Direitos do Cidadão. Revisão do Planejamento Temático da Procuradoria Federal dos Direitos do Cidadão, 2014c. Disponível em: <http:// pfdc.pgr.mpf.mp.br/institucional/a-procuradoria-federal/a-pfdc/planejamento-tematico/ planejamento-2015-2016>.Acesso em: jan. 2018. 
Procuradoria Federal dos Direitos do Cidadão. Relatório de execução do Planejamento Temático da PFDC -Exercício de 2013. 2014d. Disponível em: <http://pfdc. pgr.mpf.mp.br/institucional/a-procuradoria-federal/a-pfdc/planejamento-tematico/relatorioplanejamento-tematico2013>. Acesso em: jan. 2018.

Procuradoria Federal dos Direitos do Cidadão. Relatório de Atividades, $2013 a$. Disponível em: < http://pfdc.pgr.mpf.mp.br/institucional/relatorio_atividades/2013/2013portugues $>$. Acesso em: set. 2017.

1aㅡ Câmara de Coordenação e Revisão. Relatório de Atividades, 2013b. Disponível em <http://www.mpf.mp.br/atuacao-tematica/ccr1/atos-e-publicacoes/relatorio-de-atividades/ relatorio-de-atividades-documentos/relatorio-de atividades 2013.pdf>. Acesso em: set. 2017.

. Ministério Público Federal. Governança, gestão, inovação e resultados: biênio 2011 -2013. Brasília: MPF, 2013c. 172 p.

Núcleo de Apoio Operacional. Apresentação. Disponível em: <http://www.mpf. $\mathrm{mp}$.br/atuacao-tematica/pfdc/sobre/nucleos-de-apoio-operacional-a-pfdc-naops $>$. Acesso em: mar. 2018.

.Uma construção coletiva: planejamento estratégico 2011-2020. Brasília:SecretariaGeral, 2011a.112 p. Disponível em:<http://www.mpf.mp.br/conheca-o-mpf/gestao-estrategica-emodernizacao-dompf/sobre/publicacoes/pdf/livroplanejamentoestrategicodiadaestrategica. pdf/view> .Acesso em: dez. 2017.

Planejamento Estratégico Institucional: Informações úteis para o dia a dia de trabalho.Brasília-DF. 2011b. 42 p. Disponível em: <http://www.mpf.mp.br/conhecao-mpf/gestao-estrategica-e-modernizacao-do-mpf/sobre/publicacoes/pdf/cartilha planejamento_105_online.pdf $>$. Acesso em: mar. 2018.

MINISTÉRIO DA SAÚDE. Sistema Único de Saúde, 2o18a. Disponível em: <http://portalms. saude.gov.br/index.php/sistema-unico-de-saude/sistema-unico-de-saude>. Acesso em mar. 2018.

Farmácia Popular, 2o18b. Disponível em: <http://portalms.saude.gov.br/acoes-eprogramas/farmacia-popular>.Acesso em mai. 2018.

NETO. O. B. A jurisprudência dos Tribunais Superiores e o direito à saúde -evolução rumo à racionalidade. Revista de Direito Sanitário, São Paulo v.16 n.1, p. 87-111, mar./jun. 2015.

NOGUEIRA, K. W. A.; JÚNIOR, G. M.; SILVA, A. M. V. Subfinanciamento crônico do Sistema Único de Saúde: a persistência de uma velha agenda para o sistema. Anais $7^{\circ}$ Seminário Nacional contra a privatização da saúde. Disponível em: <http://www.seer.ufal.br/index. php/anaisseminariofncps/article/view/3964>. Acesso em: mar. 2018.

OLIVEIRA, J. E. Constituição federal anotada e comentada: doutrina e jurisprudência. Rio de Janeiro: Forense, 2013. 
OLIVEIRA, F. F. O Ministério Público resolutivo: a tensão entre a atuação preventiva ea autonomia institucional. In: ALMEIDA, G. A. (Coord.). Teoria Geral do Ministério Público. Belo Horizonte: Del Rey, 2013. p. 238-256.

SENADO FEDERAL. Em discussão. Revista de Audiências Públicas do Senado Federal, Ano 5, no 19, fevereiro de 2014. Disponível em: <http://www.senado.gov.br/noticias/jornal/emdiscussao/ Upload/201401\%20-\%2ofevereiro/pdf/em\%2odiscuss\%C3\%A3o!_fevereiro_2014_internet. pdf>. Acesso em: mar. 2018.

TRIBUNAL DE CONTAS DA UNIÃO. Acórdão1130/2017-Plenário.Relator: Bruno Dantas. Processo 011.770/2015-5. Data da sessão 31/05/2017. Número da ata 19/2017. Disponível em: <https://contas.tcu.gov.br/pesquisaJurisprudencia/\#/ detalhamento/11/\%252a/NUMACORDAO\%253A1130\%2520ANOACORDAO\%253A2017/ DTRELEVANCIA\%2520desc\%252C\%2520NUMACORDAOINT\%252odesc/false $/ 1 /$ false $>$. Acesso em: mar. 2018. 